\title{
Understanding resilience of female adolescents towards teenage pregnancy: a cross-sectional survey in Dar es Salaam, Tanzania
}

\author{
Constanze Pfeiffer ${ }^{1,2^{*}}$ D, Collins K Ahorlu ${ }^{3}$, Sandra Alba ${ }^{1,2,5}$ and Brigit Obrist ${ }^{1,2,4}$
}

\begin{abstract}
Background: In Tanzania, teenage pregnancy rates are still high despite the efforts being made to reduce them. Not enough is known about how adolescents experience and cope with sexuality and teenage pregnancy. Over the past few decades, most studies have focused on vulnerability and risk among youth. The concept of 'reproductive resilience' is a new way of looking at teenage pregnancy. It shifts the perspective from a deficit-based to a strength-based approach. The study presented here aimed to identify factors that could contribute to strengthening the reproductive resilience of girls in Dar es Salaam, Tanzania.

Methods: Using a cross-sectional cluster sampling approach, 750 female adolescents aged 15-19 years were interviewed about how they mobilize resources to avoid or deal with teenage pregnancy. The main focus of the study was to examine how social capital (relations with significant others), economic capital (command over economic resources), cultural capital (personal dispositions and habits), and symbolic capital (recognition and prestige) contribute to the development of adolescent competencies for avoiding or dealing with teenage pregnancy and childbirth.

Results: A cumulative competence scale was developed to assess reproductive resilience. The cumulative score was computed based on 10 competence indicators that refer to the re- and pro-active mobilization of resources. About half of the women who had never been pregnant fell into the category, 'high competence' (50.9\%), meaning they could get the information and support needed to avoid pregnancies. Among pregnant women and young mothers, most were categorized as 'high competence' (70.5\%) and stated that they know how to avoid or deal with health problems that might affect them or their babies, and could get the information and support required to do so. Cultural capital, in particular, contributed to the competence of never-pregnant girls $[\mathrm{OR}=1.80,95 \% \mathrm{Cl}=1.06$ to $3.07, p=0.029]$, pregnant adolescents and young mothers $[\mathrm{OR}=3.33,95 \% \mathrm{Cl}=1.15$ to $9.60, p=0.026]$.

Conclusions: The reproductive resilience framework provides new insights into the reproductive health realities of adolescent girls from a strength-based perspective. While acknowledging that teenage pregnancy has serious negative implications for many female adolescents, the findings presented here highlight the importance of considering girls' capacities to prevent or deal with teenage pregnancy.
\end{abstract}

Keywords: Resilience, Adolescents, Sexual and reproductive health, Quantitative methods, Tanzania, Urban health

\footnotetext{
* Correspondence: constanze.pfeiffer@unibas.ch

1 Department of Epidemiology \& Public Health (EPH), Swiss Tropical and

Public Health Institute (Swiss TPH), Socinstr. 57, P.O. Box 4002, Basel,

Switzerland

${ }^{2}$ University of Basel, Petersplatz 1, 4003 Basel, Switzerland

Full list of author information is available at the end of the article
} 


\section{Plain English summary}

Despite efforts to reduce teenage pregnancy rates in Tanzania, they are still high. Not enough is known about how female adolescents experience and cope with sexuality and teenage pregnancy. Over the past few decades, most studies have focused on vulnerability and risk among youth. The concept of 'reproductive resilience' is a new way of looking at teenage pregnancy. It shifts the perspective from a deficit-based to a strength-based approach. The study presented here aimed to identify factors that could contribute to strengthening the reproductive resilience of girls in Dar es Salaam, Tanzania.

Using a cross-sectional cluster sampling approach, 750 female adolescents aged 15-19 years were interviewed about how they mobilize resources (such as social, economic, cultural, and symbolic capital) to avoid or deal with teenage pregnancy.

About half of the women who had never been pregnant fell into the category, 'high competence' (50.9\%), meaning they could get the information and support needed to avoid pregnancies. Among pregnant women and young mothers, most were categorized as 'high competence' (70.5\%), and stated that they know how to avoid or deal with health problems that might affect them or their babies and could get the required information and support. Cultural capital, in particular, contributed to the competence of neverpregnant girls, pregnant adolescents and young mothers.

The reproductive resilience framework provides new insights into the reproductive health realities of adolescent girls. The findings highlight the importance of considering girls' capacities to deal with teenage pregnancy.

\section{Background}

Young people hold the key to the future, yet they face multiple and complex challenges. From a public health perspective, a key concern is the sexual and reproductive health of youth [1]. According to the United Nations (UN) the term "young people" is used for the age range 10 to 24 . This group can be divided into three subgroups: younger adolescents (10 to 14 years); older adolescents (15 to 19 years); and youth (15 to 24 years) [1]. Adolescents especially in low-and middle-income countries are considered to be one of the most at-risk groups as far as sexual and reproductive health risks are concerned [1-4]. Pregnancy exposes adolescent women to medical, social and economic threats, as they have a high risk of dying in childbirth, of being socially excluded and of living in poverty as single mothers [2].

Due to rapid urbanization in developing countries, many adolescents grow up in urban areas. Despite the high and growing number of urban youth, not enough is known about their health and their sexual and reproductive health, in particular $[5,6]$.

In the past, adolescents have often been represented as being very vulnerable to sexual and reproductive health risks [1-3, 7-9]. Such thinking is rooted in a developmentalist framework that constructs adolescence as a separate stage of development during which adolescents are no longer children, but not yet adults [10]. This Western notion of adolescence [11], however, ignores the fact that childhood and adolescence mean different things in different contexts [10]. In Tanzania, for instance, marital status and motherhood shape whether adolescents are regarded as grown-ups or not.

Nevertheless, the developmentalist discourse is still reflected in some public health discussions and influences policy and practice [10]. Recently, however, discussions around the post-2015 health agenda for women, children, and adolescents highlighted the importance of a paradigm shift from problemoriented approaches towards those that emphasize resilience and capacity among young people [12].

While this study does not ignore the various risks related to teenage pregnancy, it argues that by focusing only on adolescents' problems or weaknesses, their strengths and capacities might be overlooked [13, 14]. In line with Harpham, it contends that, 'we need to know what to strengthen among low-income urban populations to protect and promote their health, and how to strengthen it. This requires information about resilience rather than vulnerability' ([5]: p. 115).

A strength-based approach focusing on resilience has a long history in child development psychology [15-21]. Our current understanding of resilience comes from a small community of Western-trained psychologists and social workers in the United States and Europe [22]. Only in the last few years have psychologists expanded their research to include low- and middle-income countries [22-24]. Recently, a group of social scientists from Switzerland conceptualized resilience from a social science perspective [25] and proposed a multi-layered social resilience framework. Drawing on theories of structuration and social constructivism, they acknowledge that resilience is a scientific construct that is influenced by the values of those who define it [26-30]. Moreover, they put human agency in the face of threats at the centre of their research and acknowledged that this capacity is shaped by access to various capitals, as defined by Bourdieu [29]. They, thus define social resilience as, 'the capacity of actors to access capitals in order to - not only cope with and adjust to adverse conditions (i.e. reactive capacity) - but search for and create options (i.e. proactive capacity), and thus develop increased competence (i.e. positive outcomes) in dealing with a threat. 
Access to economic, social and cultural capitals is to a large extent structured by power-related symbolic capital' ([25]: p. 289-290).

While the concept of sexual and reproductive health covers a broad range of issues around pregnancy, this study focused on teenage pregnancy among adolescent girls aged 15 to 19 years, in two urban and two rural areas in Ghana (Accra and Begoro) and Tanzania (Dar es Salaam and Mtwara Town). It is widely acknowledged that reproductive health research should target women and men [31], however, this study focused on female adolescents as the individuals most immediately and directly impacted by teenage pregnancy. This study examined whether and how actors (family, peers, teachers, etc.) as well as institutions and organizations (health services, schools, youth development projects, etc.) influence adolescent women's competence in avoiding or dealing with teenage pregnancy. While the study used quantitative and qualitative methods, this article presents the quantitative results from the urban site in Dar es Salaam, Tanzania. Findings from the urban setting in Ghana have been presented elsewhere [32]. Qualitative studies were also conducted in Tanzania and Ghana to complement the quantitative findings. These results are reported elsewhere [33].

\section{Conceptual framework}

This study started from the dominant public health assumption that unwanted and unplanned pregnancy may threaten the health, education, and socio-economic wellbeing of adolescent women $[3,9]$. Thus, the project focused on unwanted and unplanned teenage pregnancy as a potential threat to female adolescents. Drawing on the social resilience approach [25], the study examines how adolescent women build resilience to this threat at the household level, with a particular emphasis on 1) their social, economic, cultural and symbolic capital; 2) their personal capacities; 3) their socio-demographic context; and 4) the outcome: competence (ability to competently deal with the threat of teenage pregnancy) (Fig. 1).

Building on the work of Pierre Bourdieu [29, 30], capital is understood as material and non-material resources that determine human agency. He distinguishes four types of capital. Economic capital refers to the command over economic resources such as cash and assets. Social capital is defined as the various kinds of valued relations with significant others. Cultural capital is divided into three forms: embodied (personal dispositions and habits), objectified (knowledge and tradition stored in material forms) and institutionalized (educational qualification). Bourdieu later added symbolic capital (honor, recognition, and prestige) - a power-related resource that influences the ways in which actors can access other forms of capital. Capital is continuously attained, transferred, transformed, and repositioned. Although this

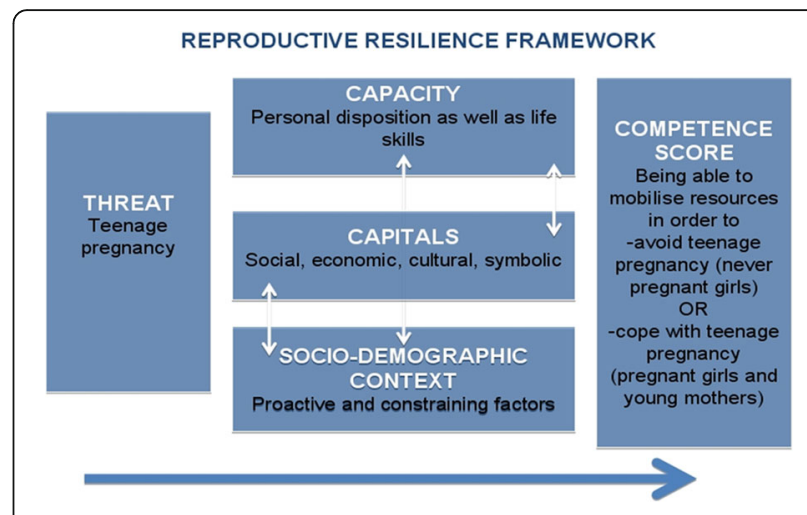

Fig. 1 Reproductive resilience framework (modified multi-layered social resilience framework by Obrist, Pfeiffer \& Henley, 2010)

short description simplifies Bourdieu's work, it allows for a conceptualization of social resilience [25].

According to Bourdieu [29, 30], individual actors are constrained by structures but, at the same time, can reshape existing structures. The human capacity to reflect and act in relation to a threat is both structured by and structures economic, social, and cultural capital. The definition of capacities moves beyond the common concept of attributes and personal dispositions used in psycho-social resilience scales [34] and allows for the inclusion of life skills. Life skills refer to various abilities for adaptive behavior [35] such as the capacity to decide freely with whom to have sex.

In line with the social resilience approach, the study focused on competence as an outcome of resilience. In order to highlight the re- and pro-active component of social resilience, the competence score was based on the following outcome: being able to competently mobilize resources in order to avoid teenage pregnancy (for never pregnant adolescents) or to cope with teenage pregnancy (for pregnant girls and young mothers).

This paper focuses on the role of different types of capital and its impact on the competence score. It is hypothesized that:

(1) Adolescents can develop competencies for dealing with the threat of teenage pregnancy.

(2)Mobilizing capital (economic, social, cultural, and symbolic resources) increases adolescents' competence in avoiding or dealing with teenage pregnancy.

\section{Methods}

Design

The study focused on female adolescents aged 15-19 years, who form part of the older adolescent age group according to the World Health Organization (WHO) [36]. In this article, the terms "adolescents" and "girls" are used interchangeably and refer to the WHO definition of older 
adolescents. A cross-sectional survey was conducted with female adolescents from Dar es Salaam, Tanzania. In order to gain insights into female adolescents' resilience, the girls were asked a series of questions on how they dealt with sexuality, unwanted/ unplanned teenage pregnancy, and teen motherhood (Table 1). The questionnaire used precoded multiple responses.

\section{Study setting and sampling}

Dar es Salaam is the largest city in Tanzania. It is divided into three municipalities: Kinondoni, Ilala, and Temeke. According to the 2012 census, Dar es Salaam Region has a population of 4,364,541 ([37]: p. 2). Although Dar es Salaam is not the official capital city, it is the largest city in the country.

A total of 750 respondents were included in the study. To attain the required sample size for the study, taking into account the female adolescent population (160'266) and teenage pregnancy rate (15\%) in Dar es Salaam, 12 clusters - four in each of the three municipalities in Dar es Salaam (Map 1) - were randomly selected. Sample size considerations were based on recommendations that a logistic regression analysis should have at least 10 cases for each explanatory variable [28]. It was estimated that aproximately $30 \%$ of respondents would be considered cases ('high competence', see Data Analysis section for details) and that approximately 20 variables would be included in the final multivariate regression model. In addition, a 10\% non-response rate was allowed.
A one-stage cluster sampling approach was used to select respondents in Dar es Salaam. The second smallest administrative units in the city, the sub-wards or Mtaa/ Mitaa (Kiswahili for "street/streets"), were used as clusters in all three municipalities (Kindondoni, Ilala and Temeke). Twelve clusters, four in each of the three municipalities in Dar es Salaam (Map 1), were randomly selected. Within each cluster, all households with female adolescents aged 15-19 years were visited and, based on their willingness to participate, they were included in the study [38, 39]. The research team stopped going to households only after all clusters were covered completely. Married girls could be well covered through this approach as most of them either stayed with their family or their partner's family. In each cluster, an average of 63 adolescents were sampled. At the end of the fieldwork, only six girls could not be included in the study because their caretakers refused to give consent.

\section{Data generation}

Prior to data collection the questionnaire was pre-tested and revised accordingly. From November 2010 to January 2011, data collection was conducted by adolescent women, aged 19 to 24 years. A peer-to-peer data collection approach was chosen to reduce age-related social barriers and to increase trust between interviewees and interviewers. The six data collectors were trained during a three-day training workshop in Dar es Salaam and supervised during data collection. Continous monitoring of data collection and weekly exchanges between project

Table 1 Reproductive resilience research design ${ }^{a}$

\begin{tabular}{|c|c|}
\hline Variables & Questions (selection of few examples) \\
\hline \multicolumn{2}{|c|}{ 1. Socio-demographic background } \\
\hline $\begin{array}{l}\text { Socio demographic } \\
\text { background }\end{array}$ & How old are you? Are you in a relationship? \\
\hline \multicolumn{2}{|l|}{ 2. Capitals } \\
\hline 2.1 Social capital & $\begin{array}{l}\text { Do you have someone you can turn to in case you have questions related to avoiding/dealing with teenage pregnancy? } \\
\text { Whom do you turn to? }\end{array}$ \\
\hline 2.2 Cultural capital & $\begin{array}{l}\text { Do you have access to other information sources in order to learn about how to avoid/deal with teenage pregnancy? } \\
\text { What kind of sources? }\end{array}$ \\
\hline 2.3 Economic capital & $\begin{array}{l}\text { Do you have someone you can turn to in case you need money to avoid/deal with teenage pregnancy? Whom do } \\
\text { you turn to? }\end{array}$ \\
\hline 2.4 Symbolic capital & Do you feel accepted within your social environment? Do you strive for a good reputation? \\
\hline \multicolumn{2}{|l|}{ 3. Capacities } \\
\hline 3.1 Psycho-social dispositions & $\begin{array}{l}\text { Do you belief that you can successfully manage to avoid/deal with teenage pregnancy? Do you have the ability to } \\
\text { establish and maintain relationships to people? }\end{array}$ \\
\hline 3.2 Life skills & $\begin{array}{l}\text { Do you know how to protect yourself from pregnancy? Do you decide freely if, when and with whom you want to } \\
\text { have sex? }\end{array}$ \\
\hline \multicolumn{2}{|l|}{ 4. Competence score } \\
\hline Competence & $\begin{array}{l}\text { Have you mobilized any social/economic/cultural support in order to actively avoid teenage pregnancy/deal with } \\
\text { teenage pregnancy? }\end{array}$ \\
\hline
\end{tabular}

${ }^{a}$ This paper focuses on the impact of capitals (highlighted in italics) on competence (highlighted in italics) 


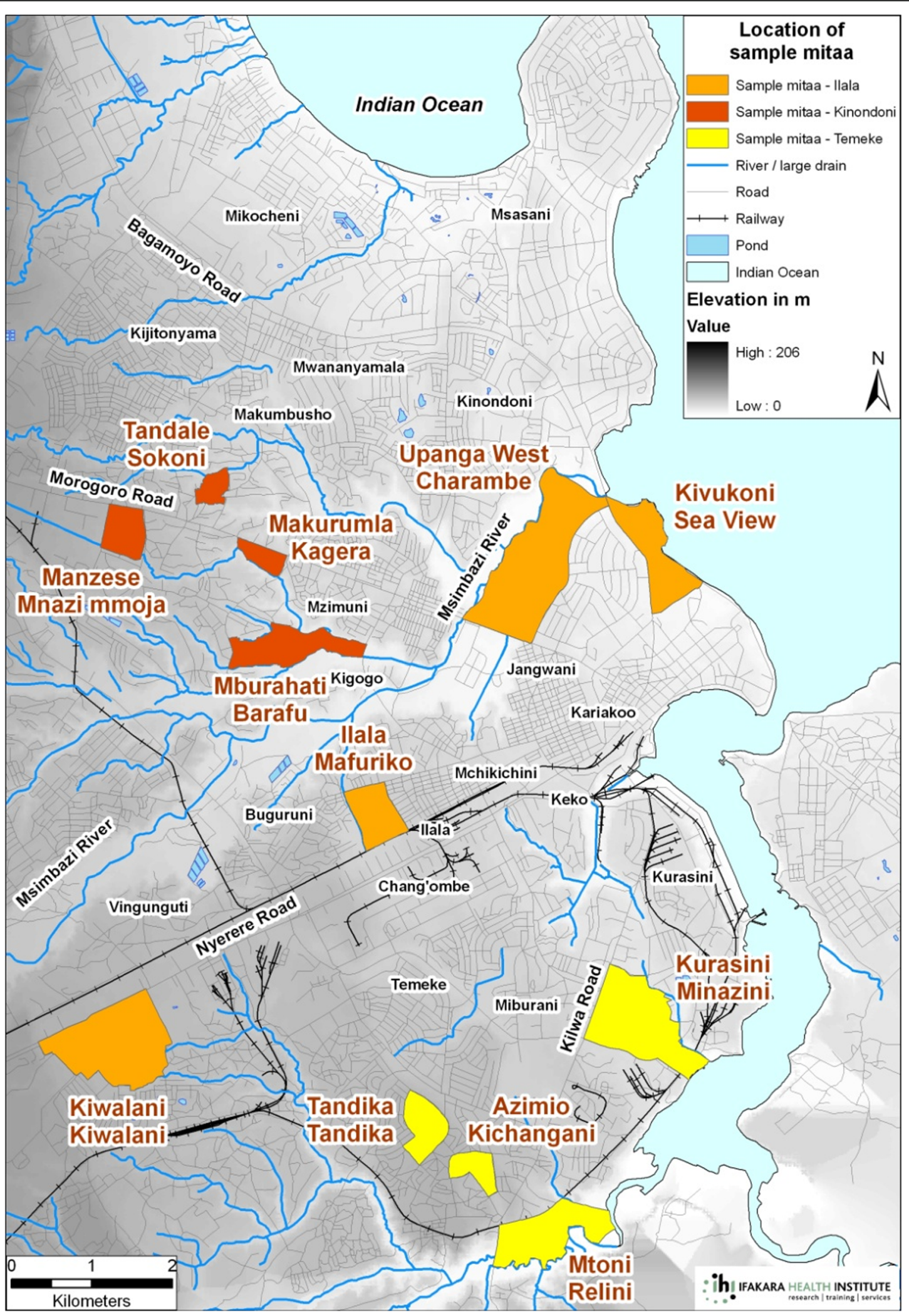

Map 1 Selected administrative units (Mitaa) in the city of Dar es Salaam 
leader, field supervisor, and data collectors aimed to guarantee quality.

\section{Data analysis}

A cumulative competence scale was developed as outcome to assess reproductive resilience. The cumulative score was computed based on 10 competence indicators that refer to the re- and pro-active mobilization of resources. Depending on pregnancy status (never pregnant vs. pregnant adolescents and young mothers), a set of questions related to competence were asked (Table 1). The questions were carefully discussed within the research team, comprising Tanzanian, Ghanaian, and Swiss social scientists, and statisticians as well as Tanzanian adolescent data collectors. Particular attention was given to the local context, including suitability of terms and local concepts of teenage pregnancy. The questions were pre-tested and discussed with Tanzanian adolescents and revised thorougly.

Each competence question answered with 'yes' (i.e. having actively mobilized resources, continued education, etc.) contributed '1'; questions answered with 'no' (i.e. not having actively mobilized resources, did not continue with education, etc.) contributed ' 0 ' to the score. Each respondent among the pregnant girls and young mothers could score a minimum of 0 (all questions answered with 'no') and a maximum of 10 (100\%) (all questions answered with 'yes'). For the purpose of this analysis, a score of $\leq 50 \%$ was indicative of 'low competence in mobilizing resources to avoid or deal with pregnancy', while a score of $51-100 \%$ was considered as 'high competence in mobilizing resouces to avoid or deal with pregnancy'. A 50\% cut-off point was used in order to learn about the broad spectrum of competencies among respondents. No reliability testing was performed for score development.

Statistical analyses were conducted using IBM SPSS Statistics 19 and included descriptive statistics, chi-square tests, as well as univariate and multivariate logistic regressions. Bivariate relationship between competence score and capital variables, competence score and ability variables as well as competence score and demographic variables were computed. Variables for the logistic models to identify determinants of resilience were identified by suggestive bivariate relationships. All logistic regression models were controlled for age, since proportionally more never pregnant girls were in the younger age than the pregnant/young mothers. The outcome variable of the study was the ability to avoid pregnancy or cope well with it, which was expressed in the competence scores.

The logistic regressions were fitted to assess the effect of social, cultural, economic, and symbolic capital variables on the odds of being in a high vs. low competence score category. All variables with $p \leq 10 \%$ in univariate analyses were entered in the mulitviariate model. Analyses were conducted separately by pregnancy status in order to gain insights into the different health realities of non-pregnant female adolescnts compared to pregnant girls and young mothers. Only results from the multivariate logistic regression analysis are presented in this paper.

\section{Results}

\section{Socio-demographic context of respondents}

Of the 750 sampled teenagers, $16 \%(n=112)$ reported that they were pregnant or already mothers. Table 2 shows respondents' sociodemographic characteristics by

Table 2 Socio-demographic characteristics of respondents, by pregnancy status

\begin{tabular}{|c|c|c|c|c|}
\hline \multirow[t]{2}{*}{ Categories } & \multicolumn{2}{|c|}{$\begin{array}{l}\text { Never pregnant } \\
\text { girls }\end{array}$} & \multicolumn{2}{|c|}{$\begin{array}{l}\text { Pregnant girls and/o } \\
\text { young mothers }\end{array}$} \\
\hline & $\begin{array}{l}n \\
(N=638)\end{array}$ & $\%$ & $\begin{array}{l}n \\
(N=112)\end{array}$ & $\%$ \\
\hline \multicolumn{5}{|l|}{ Age } \\
\hline 15 Years & 167 & 26.2 & 1 & 0.9 \\
\hline 16 years & 107 & 16.8 & 11 & 9.8 \\
\hline 17 years & 114 & 17.9 & 8 & 7.1 \\
\hline 18 years & 108 & 16.9 & 20 & 17.9 \\
\hline 19 years & 142 & 22.3 & 72 & 64.3 \\
\hline \multicolumn{5}{|l|}{ Education } \\
\hline Primary education & 277 & 43.4 & 85 & 75.9 \\
\hline Secondary education & 326 & 51.3 & 21 & 18.8 \\
\hline Vocational training & 13 & 2.0 & 0 & 0 \\
\hline No education & 21 & 3.3 & 6 & 5.4 \\
\hline \multicolumn{5}{|l|}{ Relationship status } \\
\hline Single & 367 & 57.5 & 11 & 9.8 \\
\hline In a relationship/not married & 258 & 40.4 & 57 & 50.9 \\
\hline Married & 13 & 2.0 & 38 & 33.9 \\
\hline Divorced/separated & 0 & 0 & 6 & 5.4 \\
\hline \multicolumn{5}{|c|}{ Both parents of respondent living together with their children } \\
\hline Yes & 372 & 58.3 & 53 & 47.3 \\
\hline No & 169 & 26.5 & 43 & 38.4 \\
\hline Others (dead, don't know) & 87 & 15.2 & 16 & 14.3 \\
\hline \multicolumn{5}{|c|}{ Respondent's father has more than one wife } \\
\hline Yes & 213 & 33.4 & 37 & 33.0 \\
\hline No & 327 & 51.3 & 58 & 51.8 \\
\hline Others (dead, don't know) & 98 & 15.4 & 17 & 15.2 \\
\hline \multicolumn{5}{|l|}{ Religion } \\
\hline Christians & 207 & 32.4 & 27 & 24.1 \\
\hline Muslims & 428 & 67.1 & 85 & 75.9 \\
\hline Others & 3 & 0.5 & 0 & 0 \\
\hline
\end{tabular}


pregnancy status. Younger girls were more likely to be categorized as never pregnant and not in a relationship. Most of the married girls reported to be pregnant before marriage. Adolescents with less education were more likely than better-educated girls to have started bearing children. At the same time, the data indicates that early childbearing leads to school dropouts. Contrary to Ghana, where a similar study was conducted [32], the education policy in Tanzania until recently stated that girls who became pregnant in school were to be expelled and not allowed to return following their pregnancy. In 2009, the "Law of the Child" Act, 351 was passed by the Tanzanian parliament, which amends this policy and allows girls to return to school. However, it is still unclear whether it will actually be enforced.

\section{Competence of female adolescents}

Both groups of adolescent women, especially those who were pregnant or already mothers, had high competence scores. About half of the women who had never been pregnant fell into the category of 'high competence' (50.9\%), meaning they could get the information and support they needed to avoid pregnancies. Among pregnant women and young mothers, even more respondents had 'high competence' levels (70.5\%) compared to the female adolescents you had never been pregnant; the majority stated that they know how to avoid or deal with health problems that might affect them or their babies and could get the information and support to do so.

\section{Social Capital}

Depending on their pregnancy status, female adolescents in Dar es Salaam turned to different social actors, mainly their parents and peers, when in need of information on how to avoid or deal with teenage pregnancy. In former times, other relatives - aunts, in particular - were approached, but due to societal changes and new family structures (moving from extended to nuclear families because of modernity and increasing mobility) parents are increasingly contacted [12, 40, 41]. This transition was confirmed by both groups in the study (Fig. 2). However, Table 3 shows that parents/guardians in Dar es Salaam did not contribute significantly to female adolescents' competence level. Interviewed girls in Dar es Salaam did not talk to their peers (22\% never pregnant girls; $18 \%$ pregnant girls and young mothers) about sexual matters as often as to their parents or relatives (51\% never pregnant girls; $53 \%$ pregnant girls and young mothers). Although it can be concluded that individual actors can contribute to the competence of girls, the quality of information in terms of accuracy and reliability was not covered in this study.

\section{Cultural Capital}

In a context where family members, partners, and peers may not offer reliable information about sexual health and pregnancy, additional sources of information such as mass media become important for youth [9]. A logistic regression including social (having someone to turn to for social support), economic (having someone to turn to for economic support), cultural (having access to other sources of information), and symbolic capital (being accepted by others) showed that only cultural capital contributed to the competence of never pregnant girls $[\mathrm{OR}=1.80,95 \% \mathrm{CI}=1.06$ to $3.07, p=0.029]$ as well as to pregnant adolescents and young mothers $[\mathrm{OR}=3.33$, $95 \% \mathrm{CI}=1.15$ to $9.60, p=0.026]$ (Table 3). This finding highlights the importance of cultural capital as a determinant for reproductive resilience. Table 3 provides information about the contribution of different types of media to the competence of young people. Music and the Tanzanian magazines, Fema and Si Mchezo!, published by Femina HIP, contributed significantly to the competence of never pregnant girls. Femina HIP is the biggest local multimedia platform and civil society organization working with youth, communities, and partners in Tanzania. It publishes Fema and Si Mchezo!, the top two magazines in Tanzania for 15 to 25 year

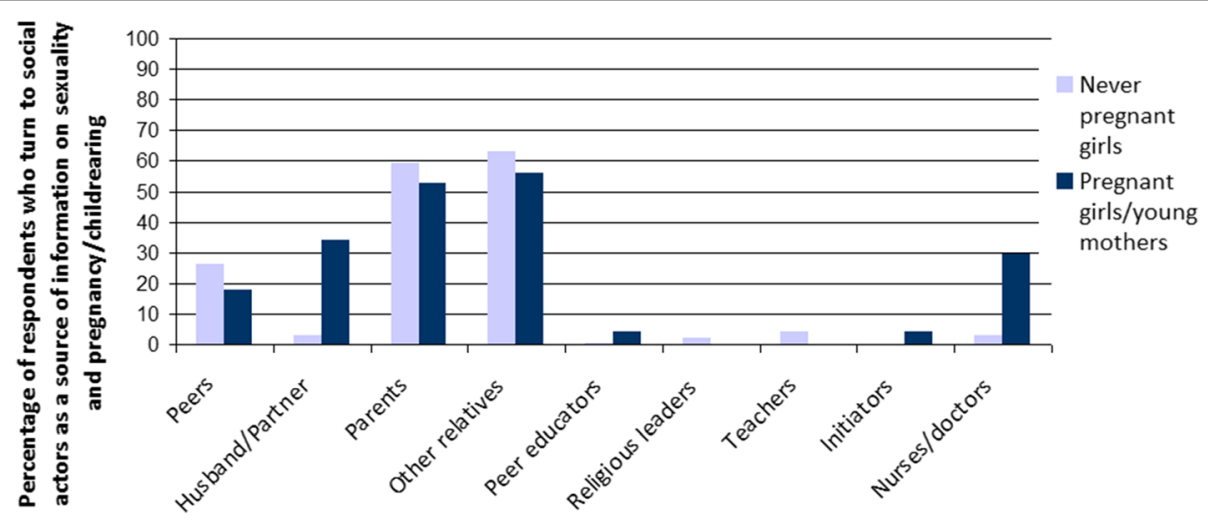

Fig. 2 Access to social actors by pregnancy status 
Table 3 Multivariate logistic regression analysis: Estimated effect of social, cultural and economic capital on the competence score, by pregnancy status

\begin{tabular}{|c|c|c|c|c|c|c|c|c|}
\hline & Never & girls (N & & & $\begin{array}{l}\text { Pregn } \\
\text { young }\end{array}$ & $\begin{array}{l}\text { and/o } \\
\text { s }(N=\end{array}$ & & \\
\hline & $\overline{O R}$ & $95 \%$ & C.I. & $p$-Value & OR & $95 \%$ & C.I. & $p$-Value \\
\hline Social capital & 1.40 & 0.875 & 2.25 & 0.159 & & & & \\
\hline Peers $^{\mathrm{b}}$ & 1.71 & 1.18 & 2.48 & 0.004 & & & & a \\
\hline Partner ${ }^{b}$ & 2.07 & 0.76 & 5.65 & 0.157 & & & & $a$ \\
\hline Parents/guardians ${ }^{b}$ & 1.34 & 0.97 & 1.86 & 0.077 & & & & a \\
\hline Other relatives ${ }^{b}$ & 0.87 & 0.62 & 1.22 & 0.414 & & & & a \\
\hline Religious leaders ${ }^{\mathrm{b}}$ & 3.36 & 0.69 & 16.36 & 0.133 & & & & a \\
\hline Teachers $^{b}$ & 1.68 & 0.69 & 4.08 & 0.258 & & & & a \\
\hline Nurses ${ }^{\mathrm{b}}$ & 1.43 & 0.51 & 4.04 & 0.495 & & & & a \\
\hline Cultural capital & 1.80 & 1.06 & 3.07 & 0.029 & 3.33 & 1.15 & 9.60 & 0.026 \\
\hline Books $^{c}$ & 1.63 & 1.05 & 2.54 & 0.031 & 2.63 & 0.30 & 23.23 & 0.383 \\
\hline Brochure ${ }^{c}$ & 1.41 & 0.75 & 2.63 & 0.286 & & & & a \\
\hline Cell Phones ${ }^{c}$ & 1.82 & 0.17 & 19.22 & 0.617 & & & & a \\
\hline Magazines $^{c}$ & 1.96 & 1.38 & 2.77 & 0.001 & 2.75 & 0.88 & 8.60 & 0.083 \\
\hline Music songs ${ }^{c}$ & 3.22 & 1.88 & 5.54 & 0.001 & 1.67 & 0.17 & 16.25 & 0.660 \\
\hline Radio $^{c}$ & 1.70 & 1.18 & 2.45 & 0.004 & 3.44 & 1.35 & 8.76 & 0.010 \\
\hline Television (TV) & 0.91 & 0.62 & 1.34 & 0.633 & 1.32 & 0.52 & 3.35 & 0.561 \\
\hline Economic capital & 0.85 & 0.39 & 1.88 & 0.692 & & & & \\
\hline Peers $^{d}$ & 3.41 & 1.73 & 6.70 & 0.001 & 1.24 & 0.22 & 7.01 & 0.809 \\
\hline Partner ${ }^{d}$ & 2.08 & 1.18 & 3.68 & 0.012 & 3.24 & 3.24 & 8.61 & 0.019 \\
\hline Parents/guardians ${ }^{d}$ & 1.31 & 0.90 & 1.01 & 0.162 & 2.98 & 2.98 & 7.58 & 0.022 \\
\hline Other relatives ${ }^{d}$ & 1.11 & 0.80 & 1.54 & 0.539 & 3.23 & 3.23 & 8.52 & 0.018 \\
\hline Religious leaders $^{d}$ & & & & a & & & & a \\
\hline Teachers $^{d}$ & 10.67 & 1.35 & 84.17 & 0.025 & & & & a \\
\hline Nurses $^{d}$ & & & & $\mathrm{a}$ & & & & $\mathrm{a}$ \\
\hline
\end{tabular}

${ }^{a}$ The variable was not entered in the logistic regression model as it was not significant according to the variable selection strategy. All variables significant at the $10 \%$ level in univariate analyses were considered candidates for the mulitviariate model

${ }^{\mathrm{b}}$ Spontaneous mention of social actors never pregnant girls and pregnant girls/young mothers turn to for information on sexuality and teenage pregnancy/childrearing 'Spontaneous mention of mass media never pregnant girls and pregnant girls/young mothers turn to for information on sexuality and teenage pregnancy/childrearing ${ }^{\mathrm{d}}$ Spontaneous mention of social actors never pregnant girls and pregnant girls/young mothers turn to for financial support related to avoiding teenage pregnancy or dealing with teenage pregnancy/childrearing

olds. Catering to secondary school students and written in English and Swahili, Fema is published quarterly and has a circulation of 180,000. Directed to out-of-school youth and written in Swahili, Si Mchezo! is published on a bi-monthly basis and has a circulation of approximately 175,000 . The two magazines also seek to reach young people in the workplace and in organizational settings.

Radio contributed to the competence of both groups, but not everyone has access to cultural capital. The findings show that $57 \%$ of never pregnant girls and $54 \%$ of their pregnant peers and young mothers had access to television (TV) (Fig. 3). Radio was used widely among young mothers or mothers to be, with $60 \%$ saying that they listen to it, while $52 \%$ of the never pregnant respondents mentioned it. Both youth magazines published by
Femina HIP were widely read; $38 \%$ of the never pregnant and $31 \%$ of the pregnant girls/young mothers stated that they read one of these magazines (Fig. 3).

While different types of media contributed to the competence of never pregnant girls, the same could not be observed for pregnant girls and young mothers, as mass media campaigns tend to target girls who are not pregnant.

\section{Economic Capital}

Access to economic resources in general did not significantly contribute to the competence of female adolescents [never pregnant girls: $\mathrm{OR}=0.85,95 \% \mathrm{CI}=0.39$ to $1.88, p=0.692$; for pregnant girls and young mothers, the variable "economic capital" could not be entered in the regression model as it was not significant in 


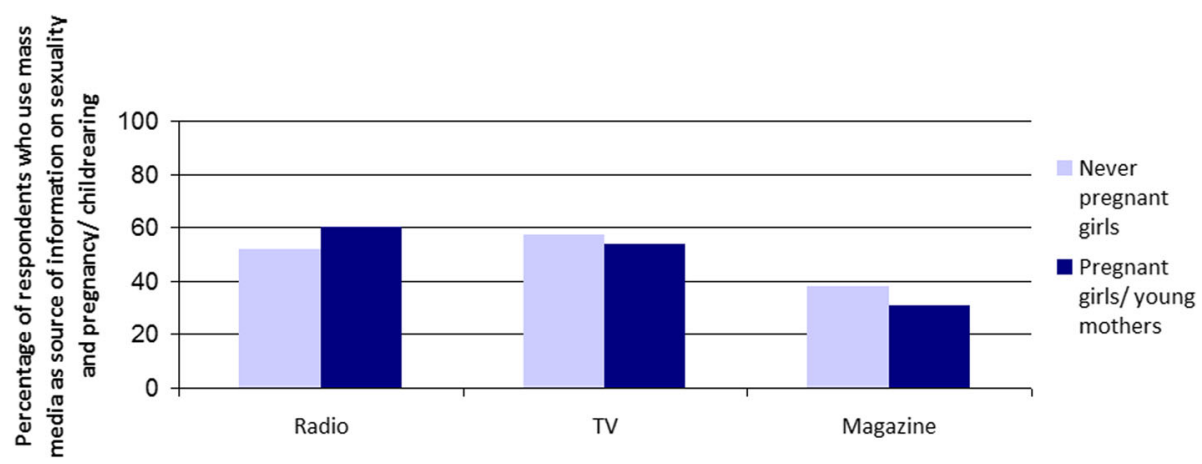

Fig. 3 Access to mass media by pregnancy status

univariate analysis] (Table 3). However, the analysis of the role of individual actors illustrated that pregnancy status considerably changed the way social actors matter for adolescent girls (Table 3). For never pregnant girls, economic capital mobilized through social actors outside the family contributed to their competence, while for pregnant girls and young mothers, economic support from family members contributed to their competence.

\section{Symbolic Capital}

Results show that almost all interviewed respondents aimed to establish symbolic capital. Some $99 \%(n=634)$ of the never pregnant girls and 98\% $(n=110)$ of the pregnant girls and young mothers 'strived for a good reputation'. In addition, regardless of their pregnancy status almost all female study participants $(99 \%, n=634$ of the never pregnant girls; $98 \%, n=110$ of the pregnant girls/young mothers) reported feeling accepted in their community. This finding highlights the importance of maintaining symbolic capital. Surprisingly, the symbolic capital of both groups of female adolescents did not significantly contribute to the competence score. Although this presentation simplifies Bourdieu's conceptualization of symbolic capital, it helps to provide insights into the different dimensions of social resilience. While findings indicate that symbolic capital does not contribute to the competence of female adolescents, it is also acknowledged that it is not easy to quantitatively capture symbolic capital in all its complexity.

\section{Discussion}

While acknowledging that teenage pregnancy often has serious negative consequences for female adolescents, this study highlights that common portrayals of adolescent mothers as unprepared 'children, who have children' might not hold true for all girls [1-3, 42, 43]. Our study shows that, in contrast to public health perceptions of teenage motherhood and in spite of the challenges some youth face, adolescent girls are not mere victims per se but also social actors that try to mobilize resources actively to secure their own health and that of their child. The higher competence score of pregnant girls and young mothers compared to peers who had never been pregnant might reflect a dynamic learning process. Due to pregnancy and motherhood, female adolescents must develop support networks and knowledge of resources in response to their situation. Thus, childbirth might be looked at as a 'turning point experience' [17: p. 136] that offers new opportunities to break away from the past [43]. What might be regarded as a threat in one situation becomes a protective factor in another. This depends on how threats and protective factors are perceived by the affected actors [43]. The psycho-social resilience literature highlights that major life transitions provide new opportunities for resilience, not only for young mothers but also for young fathers [44-47]. Findings point to factors that can further support adolescents in dealing with teenage pregnancy.

Findings show that parents/guardians in Dar es Salaam did not contribute significantly to female adolescents' competence level. A literature review [40] of parentchild communication about sexuality in sub-Saharan Africa argues that discussions on sexual matters tend to be authoritarian and vague as parents are often overwhelmed with their new roles and do not know how to provide sex education. Talking to peers significantly contributed to the competence of girls who had not been pregnant. Peers are often regarded as crucial in terms of shaping adolescent norms that serve as reference points for decision making related to health [41]. Peer communication is characterized by an open atmosphere and less restricted by cultural norms and taboos.

Cultural capital, defined as the internalization of cultural values around teenage pregnancy that are represented in media such as $\mathrm{TV}$, radio or magazines, can contribute to competence. Nichter [14] points out that local people respond practically to new information and resources, and they do so within the framework of their cultural institutions or knowledge. Using mass media is one way to make sure that adolescent women get accurate information and make informed decisions. 
This study could not confirm access to economic capital as the most important driving factor [48-50]. Cultural and social factors, especially for never pregnant girls, are equally important. This finding promotes the value of the social development debate that highlights the role of social and cultural institutions and organisations for development, in general, and for building sexual and reproductive health knowledge, in particular. Youth-focused magazines or TV programs, for instance, can build competence. However, one needs to carefully analyze who benefits from such interventions and who falls through the cracks.

\section{Reflection on the reproductive resilience framework}

The application of the reproductive resilience framework, which builds on the social resilience approach [25], proved to be useful to this study in several respects. First, the framework provides a clear definition of and highlights socio-economic and cultural aspects of reproductive resilience, thereby allowing us to move beyond existing ecological or child-development resilience concepts. Focusing on the strengths of people rather than on their weaknesses alone opens new possibilities for dealing with and reducing threats. The framework acknowledges the learning, self-organization, and creative potential of people and institutions that might be able to actively deal with threats.

Second, the framework highlights that resilience is not just about psychological traits that individuals are born with but rather that people can develop competencies that allow them to deal with a given threat. The data presented here illustrate how crucial it is to understand how and by whom these capacities are built in order to identify entry points for future interventions. This study does not, however, provide insights into whether or how these capacities are then translated into action.

Third, the framework provides new insights beyond the social or economic environment. This study makes it clear that cultural capital in terms of knowledge passed on by social and cultural institutions and organizations can significantly contribute to resilience and therefore needs to be considered in detail in resilience research.

While the reproductive resilience framework presented here offers new insights, it also has some shortcomings. The framework is grounded in the applied realm and therefore runs the risk of reducing resilience to normative and dominant concepts at the expense of the perspectives of actors [22, 25]. Although this study focused on unwanted/unplanned pregnancy, some involved female adolescents might have looked at teenage pregnancy as something that could improve their symbolic capital (their status/prestige in their community). There is clearly a need to complement experts' views of the key categories (threat, capitals, capacities and competencies) with qualitative research into local meanings corresponding with these scientific constructs.

To cover pro-active capacities, never pregnant girls were included in the study. As in other studies, these girls were interviewed in the absence of a threat that had occurred already [51, 52], which might lead to overlooking the actual context of coping with adversity ([53]: p. 754).

The study presented here used a cumulative competence scale to provide a snapshot of teenage pregnancy-related realities of girls in the urban centre of Dar es Salaam. As resilience is not a stable and durable phenomenon, longitudinal studies would be best suited to collecting reliable information [53: p. 755]. Survey data provide verifiable and generalizable data [54] but they can only generate a fraction of the information needed to understand the complexity of social institutions and relations in which reproductive practices are contextualized [55]. The quality of information adolescents received while mobilizing different capitals, in terms of accuracy and reliability, was, for instance, not covered in this study and would require deeper quantitative as well as qualitative investigation. In addition, factors other than resilience might account for the differences in the "competence scores" of female adolescents presented here. Quantitative approaches alone are not sufficient to provide insight into the full potential of agency and related creativity of actors in different contexts. Adolescent competencies in urban areas can only be adequately comprehended by understanding their everyday life, highlighting the need for culturally-adapted, mixed-methods studies.

\section{Conclusions}

This article examined how various material and nonmaterial resources can contribute to the competence of adolescents to avoid teenage pregnancy or to successfully deal with it. The reproductive resilience framework provided new insights into the resources and competencies of girls in Dar es Salaam, Tanzania. Although teenage pregnancy and motherhood involves various challenges and risks, many interviewed female adolescents tried to deal with it actively and might turn some of the challenges into opportunities [33, 56-60]. Strengthening the factors, that contribute to building competence in female adolescents, such as providing information in an appealing way through magazines, are important entry points for future interventions.

\section{Abbreviations}

TV: Television; UN: United Nations; WHO: World Health Organization

\section{Acknowledgments}

Without the great support of adolescent girls in Dar es Salaam, this project would not have been possible. We are very grateful to Trudy Harpham, Fred Krüger, Kate Molesworth, Alice Mbelwa, Boniface Kiteme, Stefan Dongus,

Richard Sambaiga, Marcel Tanner, Jakob Zinnstag, Joyce Nyoni, Rose Mwaipopo, Amena Briët and Patricia Schwärzler for comments and suggestions. 


\section{Funding}

This research was financed by the Swiss National Center of Competence in Research North-South (NCCR) North-South, an international research program of the Swiss National Science Foundation (SNSF) co-funded by the SNSF and the Swiss Agency for Development and Cooperation (SDC).

\section{Availability of data and materials}

Not applicable.

\section{Authors' contributions}

CP, CA, SA and BO conceived and designed the study. CP was responsible for project implementation, data analysis and writing the manuscript. CP, CA, $\mathrm{SA}$ and $\mathrm{BO}$ critically reviewed the manuscript and approved of it for publication.

\section{Competing interests}

The authors declare that they have no competing interests.

\section{Consent for publication}

The authors confirm that they have obtained consent to publish from the participant (or legal parent or guardian for children) to report individual patient data.

\section{Ethics approval and consent to participate}

All participants were asked for written informed consent after the purpose of the study was explained to them. For adolescents aged 18 years and above, informed consent was requested directly. If teenagers were younger than 18 years, written consent was first obtained from their parents or caretakers. In a next steps, the minors were asked whether they assented to participate. The study was conducted within the framework of the Swiss National Centre of Competence in Research (NCCR): North-South funded project "Sexual and Reproductive Resilience of Adolescents in Ghana and Tanzania". The research component in Tanzania was cleared by the National Institution for Medical Research of Tanzania (NIMR/HQ/R.8a/Nol. IX/935; NIMR/HQ/R.8c/Nol. II/33) and the Tanzanian Commission for Science and Technology (2010_311_NA_2009_86 dated 19th of October 2010).

\section{Publisher's Note}

Springer Nature remains neutral with regard to jurisdictional claims in published maps and institutional affiliations.

\section{Author details}

'Department of Epidemiology \& Public Health (EPH), Swiss Tropical and Public Health Institute (Swiss TPH), Socinstr. 57, P.O. Box 4002, Basel, Switzerland. 'University of Basel, Petersplatz 1, 4003 Basel, Switzerland. ${ }^{3}$ Noguchi Memorial Institute for Medical Research, College of Health Sciences, University of Ghana, P.O Box LG581, Legon, Ghana. ${ }^{4}$ Institute of Social Anthropology, University of Basel, Münsterplatz 19, 4051 Basel, Switzerland. ${ }^{5}$ KIT Biomedical Research, Royal Tropical Institute (KIT), Meibergdreef 39, Amsterdam 1105, AZ, The Netherlands.

\section{Received: 30 March 2016 Accepted: 9 June 2017}

\section{Published online: 26 June 2017}

\section{References}

1. World Health Organization. Building a better future for youth: learning from experiences and evidence. Geneva: World Health Organization; 2006.

2. Chandra-Mouli V, Svanemyr J, Amin A, Fogstad H, Say L, Girard F, et al. Twenty years after international conference on population and development: where are we with adolescent sexual and reproductive health and rights? J Adolesc Health. 2015;56:S1eS6

3. Bearinger $L$, Sieving RE, Ferguson J, Sharma V. Global perspective on the sexual and reproductive health of adolescents: patterns, prevention, and potential. Lancet. 2007;369:1220-321.

4. Patton GC, Sawyer SM, Santelli JS, et al. Our future: a lancet commission on adolescent health and wellbeing. Lancet. 2016;387:2423-78.

5. Harpham T. Urban health in developing countries: what do we know and where do we go? Health \& Place. 2008:15:107-16.

6. Montgomery $M$, Stren $\mathrm{R}$, Cohen $\mathrm{B}$, Reed $\mathrm{H}$. Cities transformed: demographic change and its implications in the developing World. National Academies Press, Washington, DC; 2004.
7. National Bureau of Statistics (NBS) and ORC Macro. Tanzania demographic and health survey 2004-05. Dar es Salaam: NBS and ORC Macro; 2005.

8. National Bureau of Statistics (NBS) and ICF Macro. Tanzania demographic and health survey 2010. Dar es Salaam: NBS and ICF Macro; 2011.

9. UNICEF. Adolescence in Tanzania. Dar es Salaam: United Nations Children's Fund Tanzania; 2011.

10. Macleod C. Teenage motherhood and the regulation of mothering in the scientific literature: the South African example. Feminism and Psychology. 2001;11(4):493-511.

11. Harari SE, Vinovskis MA. Adolescent sexuality, pregnancy and childbearing in the past. In: Lawson A, Rhode DL, editors. The politics of pregnancy: adolescent sexuality and public policy. New Haven \& London: Yale University Press; 1993. p. 23-45.

12. Editorial. Women, children, and adolescents: the post-2015 agenda. Lancet. 2014:384(9949):1159.

13. Tumbo-Masabo Z. Conclusions. In: Tumbo-Masabo Z, Liljeström R, editors. Chelewa, Chelewa. The dilemma of teenage girls. Östersund: Nordiska Africainstitutet; 1994. p. 211-4.

14. Nichter M. Global Health: why Cultural perceptions, social representations and Biopolitics matter. Tucson: University of Arizona Press; 2008.

15. Garmezy N. Resilience in Children's Adaptation to negative life events and stressed environments. Pediatrics. 1991;20:459-66.

16. Garmezy N. Development and Adaptation: the contribution of the MacArthur Foundation and William Bevan. In: Kessel F, editor. Psychology, science and human affairs: essays in honor of William Bevan. Boulder: Westview Press; 1995. p. 109-24.

17. Rutter M. Psychosocial resilience and protective mechanisms. Am J Orthopsychiatry. 1987:57:316-31.

18. Werner E, Smith R. Vulnerable but invincible: a study of resilient Children. New York: McGraw-Hill; 1982

19. Werner E, Smith R. Overcoming the odds: high risk Children from birth to adulthood. Ithaca: Cornell University Press; 1992.

20. Schoon M. A Short Historical Overview of the Concepts of Resilience, Vulnerability, and Adaptation. Bloomington: Workshop in Political Theory and Policy Analysis, Indiana University, Working Paper W05-4; 2005.

21. Coleman J, Haggell A, Editors. Adolescence, risk and resilience. Against the odds. Chichester: John Wiley and Sons; 2007.

22. Ungar M. Nurturing hidden resilience in troubled youth. Toronto: University of Toronto Press; 2004

23. Ungar M. Handbook for working with Children and youth - pathways to resilience across cultures and contexts. Thousand Oaks: Sage Publications; 2005

24. Ungar M, Liebenberg L. Resilience in action. Toronto: University of Toronto Press; 2008.

25. Obrist B, Pfeiffer C, Henley R. Multi-layered social resilience: a new approach in mitigation research. Prog Dev Stud. 2010;10(4):283-93.

26. Berger PL, Luckmann C. The social construction of reality: a treatise in the sociology of knowledge. New York: Anchor Books; 1966.

27. Giddens A. Central problems in social Theory. Action, structure and contradiction in social analysis. Los Angeles: University of California Press; 1979.

28. Giddens A. The constitution of society: outline of the Theory of Structuration. Cambridge: Polity Press; 1984

29. Bourdieu P. Distinction: a social critique of the judgment of taste. Cambridge: Massachussetts, Harvard University Press; 1984

30. Bourdieu P. The forms of Capital. In: Richardson JE, editor. Handbook of Theory and research for the sociology of education. New York: Greenwood Press; 1986. p. 241-58.

31. Dudgeon MR, Inhorn M. Men's influences on Women's reproductive health: medical anthropological perspectives. Soc Sci Med. 2004;59(7):1379-95.

32. Ahorlu CK, Pfeiffer C, Obrist B. Socio-cultural and economic factors influencing adolescents' resilience against the threat of teenage pregnancy: a cross-sectional survey in Accra, Ghana. Reprod Health. 2015;12:117.

33. Sambaiga R. Sexual inter-subjectivity and the quest for social well-being: an ethnographic inquiry of adolescent sexuality and reproduction in urban southern Tanzania. PhD diss. Basel: University of Basel; 2013.

34. Ahern N, Kiehl E, Sole M, Byers J. A review of instruments measuring resilience. Issues Compr Pediatr Nurs. 2006:29:103-25.

35. World Health Organization. The sexual and reproductive health of younger adolescents: research issues in developing countries. Geneva: World Health Organization; 2011. 
36. World Health Organization. The second decade: improving adolescent health and development. Geneva: World Health Organization; 2001.

37. United Republic of Tanzania. Population and housing census. Dar es Salaam: United Republic of Tanzania; 2012. p. 2012.

38. Peduzzi P, Concato J, Kemper E, Holford TR, Feinstein AR. A simulation study of the number of events per variable in logistic regression analysis. J Clin Epidemiol. 1996;49:1373-9.

39. Kish L. Survey sampling. New York: John Wiley \& Sons; 1965.

40. Bastien S, Kajula L, Muhwezi WW. A review of studies of parent-Child communication about sexuality and HIV/AIDS in sub-Saharan Africa. Reprod Health. 2011:8:25.

41. Coleman J. Free riders and zealots: the role of social networks. Sociol Theory. 1988;6:52-7.

42. Breheny M, Stephens C. Irreconcilable differences: health professionals' constructions of adolescence and motherhood. Soc Sci Med. 2007:64:112-24.

43. Collins B. Resilience in teenage mothers: a follow-up study. Wellington: Ministry of Social Development; 2010.

44. Werner EE. Protective factors and individual resilience. In: Shonkoff JP, Meisels SJ, editors. Handbook of early childhood intervention. New York: Russell Sage; 2000. p. 297-314.

45. Easterbrooks MA, Chaudhuri J, Bartlett JD, Copeman A. Resilience in parenting among young mothers: family and ecological risks and opportunities. Child Youth Serv Rev. 2010;33:42-50.

46. Marsiglio W. Studying fathering trajectories: in-depth interviewing and sensitizing concepts. In: Day RD, Lamb ME, editors. Conceptualizing and measuring father involvement. Mahwah: Erlbaum; 2004. p. 61-82.

47. Arnett JJ. Emerging adulthood: a Theory of development from the late teens through the twenties. Am Psychol. 2000;55:469-80.

48. Cleveland H, Jacobs G. Human choice: the genetic code for social development. Minneapolis: World Academy of Art \& Science, University of Minnesota; 1999

49. Ranis G, Stewart F, Ramirez A. Economic growth and human development World Dev. 2000;28(2):197-219.

50. Ranis G. Human development and economic growth. Center discussion paper no. 887. New Haven: Yale University; 2004

51. Friborg $\mathrm{O}, \mathrm{Hjemdal} \mathrm{O}$, Rosenvinge $\mathrm{JH}$, Martinussen $\mathrm{M}$. A new rating scale for adult resilience: what are the central protective resources behind healthy adjustment? Int J Methods Psychiatr Res. 2003;12(2):65-76.

52. Montross LP, Depp C, Daly J, Reichstadt J, Golshan S, Moore D, et al. Correlates of self-rated successful aging among community-dwelling older adults. Am J Geriatr Psychiatr. 2006;14(1):43-51.

53. Bonnano GA. Uses and abuses of the resilience construct: loss, trauma, and health-related adversities. Soc Sci Med. 2012;74:753-6.

54. Price N, Hawkins K. Researching sexual and reproductive behavior: a peer ethnographic approach. Soc Sci Med. 2002;55:1325-36.

55. Lockwood M. Structure and behavior in the social demography of Africa. Popul Dev Rev. 1995;21(1):1-32.

56. Vance CS. Anthropology rediscovers sexuality: a theoretical comment. Soc Sci Med. 1991;33(8):875-84.

57. Johnson-Hanks J. Uncertain honour: modern motherhood in an African crisis. Chicago: University of Chicago Press; 2006.

58. Silberschmidt $M$, Rasch V. Adolescent girls, illegal abortions and 'sugardaddies' in Dar es Salaam: vulnerable victims and active social agents. Soc Sci Med. 2001;52:1815-26.

59. Van Reeuwijk M. Because of temptations: Children, sex, and HIV/AIDS in Tanzania. Diemen: AMB Publishers; 2010.

60. Halley MC. Negotiating sexuality: adolescent initiation rituals and Cultural change in rural southern Tanzania: Case Western Reserve University; 2012.

\section{Submit your next manuscript to BioMed Central and we will help you at every step:}

- We accept pre-submission inquiries

- Our selector tool helps you to find the most relevant journal

- We provide round the clock customer support

- Convenient online submission

- Thorough peer review

- Inclusion in PubMed and all major indexing services

- Maximum visibility for your research

Submit your manuscript at www.biomedcentral.com/submit 